\title{
In vivo degradation of processed dermal sheep collagen evaluated with transmission electron microscopy
}

\author{
P.B. van Wachem, M.J.A. van Luyn and P. Nieuwenhuis \\ Department of Histology and Cell Biology, Section Biomaterials Research, University of Groningen, Oostersingel 69/2. \\ 9713 EZ Groningen, The Netherlands \\ H.K. Koerten \\ Laboratory of Electron Microscopy, University of Leiden, Rijnsburgenweg 10, 2333 A4 Leiden, The Netherlands
}

L. Olde Damink, H. Ten Hoopen and J. Feijen

Department of Chemical Technology. Twente University, PO Box 217, 7500 AE Enschede, The Netherlands

Presented at Riointeractions' 90 , Oxford, UK 21-23 August 1990

The in vivo degradation of hexamethylenediisocyanate-tanned dermal sheep collagen was studied with transmission electron microscopy. Discs of hexamethylenediisocyanate-tanned dermal sheep collagen were subcutaneously implanted in rats. Both an intra- and an extracellular route of degradation could be distinguished. In addition to normal components of a typical foreign body reaction, remarkable phenomena, such as locally deviant neutrophil morphology, infiltration of basophil-like cells, indications of foreign body multinucleate giant cells formed from different cell types, aluminium silicate accumulations and calcium phosphate depositions, were observed. Foreign body multinucleate giant cells intracellularly degraded hexamethylenediisocyanate-tanned dermal sheep collagen after internalization. Both internalized and cellularly enveloped hexamethylenediisocyanate-tanned dermal sheep collagen degraded by the detachment of fibrils. Another extracellular route of degradation was characterized by calcium phosphate depositions in large bundles of hexamethylenediisocyanate-tanned dermal sheep collagen. From 6 wk, the hexamethylenediisocyanate-tanned dermal sheep collagen implant was replaced by rat connective tissue, which was subsequently also degraded. After 15 wk, the presence of basophil-like foreign body multinucleated giant cells containing aluminium/silicon-crystalline accumulations still persisted. These phenomena were related to the specific nature of the material used and suggest cytotoxicity. They emphasize the need for detailed evaluation at the ultrastructural level of newly developed biomaterials before they can be used for medical applications.

Keywords: Collagen, biodegradation, transmission electron microscopy

\begin{abstract}
Various collagen-based biomaterials have found applications in the biomedical field ${ }^{1-3}$. Interactions between such biomaterials and tissue have been extensively described ${ }^{4-6}$. However, these reports predominantly concern light microscopy evaluations. In our opinion, more detailed knowledge of the cellular events is needed for a better understanding and further improvement of the function of collagen-based biomaterials. In this study, we used hexamethylenediisocyanate-tanned dermal sheep collagen (HDSC), which was subcutaneously implanted in rats. The material is successfully
\end{abstract}

Correspondence to Dr P.B. van Wachem. used as a biological wound dressing ${ }^{7}$. It was tested in rabbits both after intramuscular implantation of small pieces ${ }^{8}$ and after intracutaneous injections of extracts ${ }^{9}$ in accordance with US Pharmacopeia XXI (1985). The light microscopy evaluation of the intramuscular implantation test showed a very slight toxic reaction. No adverse reactions related to the material were observed in the intracutaneous injection test.

Referring to the very slight toxic reaction observed in the intramuscular implantation test, it was the aim of this study to evaluate the degradation of HDSC in detail using transmission electron microscopy (TEM). 


\section{MATERIALS AND METHODS}

\section{Materials}

Hexamethylenediisocyanate(HMDIC)-tanned dermal sheep collagen (batch Nos. 335, 339 and 392), subsequently referred to as HDSC, was obtained from the Zuid Nederlandse Zeemlederfabriek, Oosterhout, The Netherlands. The material was processed from sheep skin, which was depilated. immersed in a lime-sodium sulphide solution for removal of the epidermis and purified with proteolytic enzymes ${ }^{7}$. The skin was then split with an industrial band-knife splitting machine to obtain the dermal layer. This layer was then tanned with HMDIC (Desmodur obtained from Bayer, Germany). Discs with a diameter of $8 \mathrm{~mm}$ were punched from HDSC. The weight of the discs varied from 15 to $30 \mathrm{mg}$. Discs were sterilized by gamma irradiation (2.5 Mrad, Gammaster, Ede, The Netherlands).

\section{Methods}

Implantations. AO rats of approximately 3 month of age were used. The rats were ether anaesthesized, their backs were shaved and their skins disinfected with ethanol. Two midline incisions were made. Subcutaneous pockets were made with surgical scissors at the right and left sides of each incision. Four HDSC discs per rat were implanted in the pockets at a distance of about $1 \mathrm{~cm}$ from the incisions.

Implants with surrounding tissue were harvested at 1 , $2,3,5,7$ or $10 \mathrm{~d}$ and at every following week from 2 to $15 \mathrm{wk}$.

Microscopy. HDSC (non-implanted) and HDSC implants were fixed in $2 \%(\mathrm{v} / \mathrm{v})$ glutaraldehyde $(G A)$ in $0.1 \mathrm{~mol}$ phosphate buffered saline (PBS). Specimens were cut into small blocks $(2 \times 2 \times 2 \mathrm{~mm})$ after at least $24 \mathrm{~h}$ of fixation at $4^{\circ} \mathrm{C}$.

Blocks were post-fixed with $1 \% \mathrm{OsO}_{4}$ in PBS, dehydrated in graded alcohols and embedded in Epon 812.

Semithin sections were cut and stained with toluidine blue. Evaluation of semithin sections $(1 \mu \mathrm{m})$ provided both a light microscopical overview of cellular interactions with HDSC as well as a means of selecting those parts of blocks worth further processing for TEM. For TEM, ultrathin sections were cut and stained with uranyl acetate and lead citrate. The sections were examined with a Philips EM 201 transmission electron microscope operated at $40 \mathrm{kV}$.

Single-spot $X$-ray microanalysis was used to detect trace elements in specimens which had been implanted for $10 \mathrm{~d}, 4$ and $12 \mathrm{wk}$. Tissue blocks were fixed with GA but not with $\mathrm{OsO}_{4}$ so as to prevent the interaction of $X$-ray signals from the osmium with signals from trace elements within the specimens. Carbon-layered sections, either unstained or stained only with uranyl acetate, were analysed on a Tracor (TN) $2000 X$-ray microanalyser attached to a Philips EM 400 scanning and transmission electron microscope operated at $80 \mathrm{kV}$ and with a spot size of $100 \mathrm{~nm}$. The system geometry of the instrument has been described previously ${ }^{10}$.

\section{RESULTS}

\section{Macroscopic evaluation}

HDSC has a fibrous structure and a supple structure. Upon implantation, HDSC immediately adhered to the surrounding subcutaneous connective tissue. The HDSC discs were
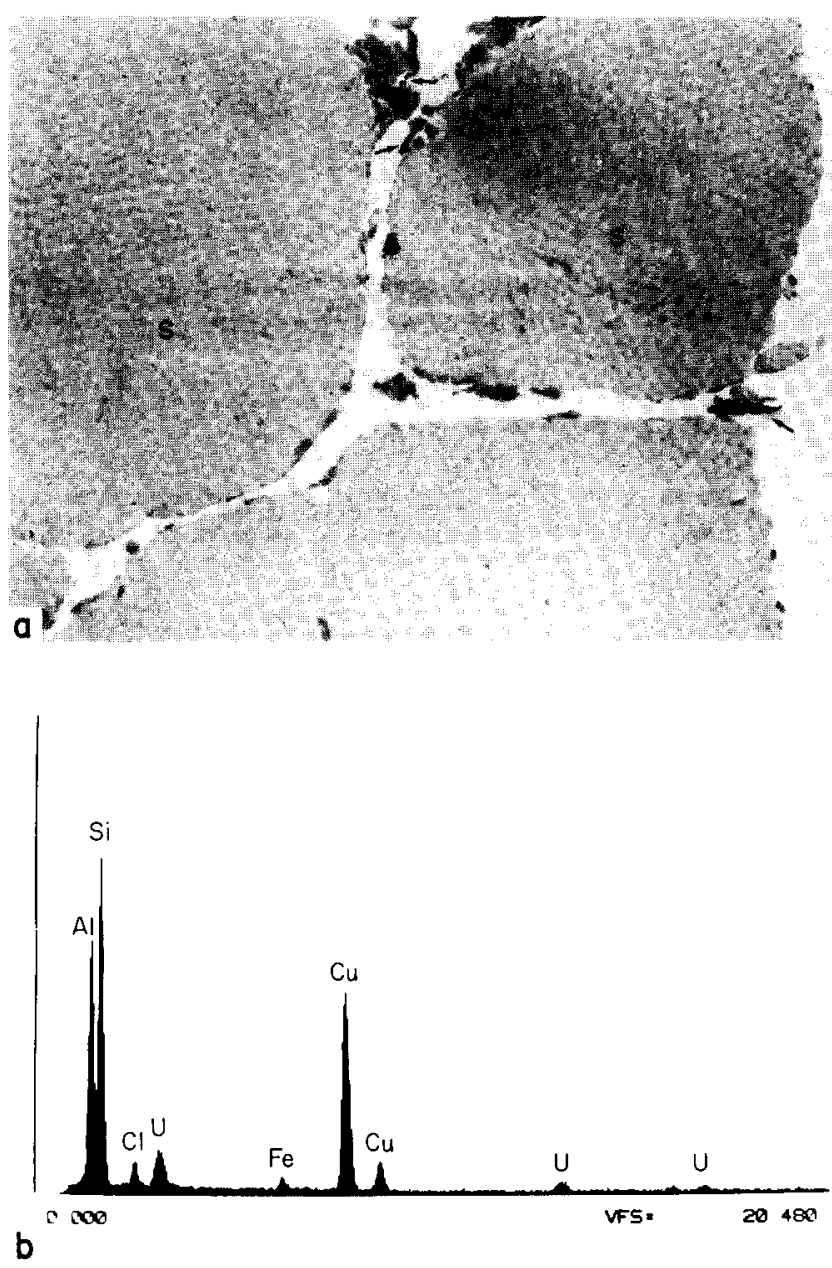

Figure 1 (a) Non-implanted HDSC with transversely cut HDSC bundles (S) and elastin (E)-like substances with sheet-like Al/Sicrystals (arrow) (original magnification $\times 17000$ ). (b) Spectrogram of crystals with aluminium (Al) and silicon (Si). The elements $\mathrm{Cl}, \mathrm{U}$ and $\mathrm{Cu}$ were derived from the preparative procedure.

easily localized by palpation during the first month. In situ inspection showed that, within days, discs had been surrounded by a rather thick fibrotic capsule. Thereafter, the thickness of the fibrotic capsule decreased. Localizing was more difficult after longer implantation intervals. From week 7, discs, or what was left of them, were sometimes hard to find.

\section{Microscopic evaluation (TEM)}

HDSC (non-implanted) mainly consists of a matrix of smaller and larger collagen bundles. Transversely cut bundles show the typical construction with collagen fibrils (Figure 1a). Furthermore, gelatinous substances, which had lost the original fibril structure, elastin-like substances lining collagen bundles (Figure 1a) and remnants of blood vessels were observed. Some electron-dense sheet-like crystalline particles, mainly in the elastin-like substances, were also present (Figure 1a). These particles contain aluminium Al and silicon $\mathrm{Si}$, observed with $\mathrm{X}$-ray microanalysis (Figure $1 \mathrm{~b}$ ), and are referred to as $\mathrm{Al} / \mathrm{Si}$-crystals.

Right after implantation the usual wound healing reaction occurred. After $1 \mathrm{~d}$, dilated blood vessels, polymorphnucleated neutrophils and macrophages with their typical small azurophilic granules were observed in the connective tissue immediately surrounding the HDSC disc. Sometimes either cell type had a deviant morphology, which will be described in detail for neutrophils below. 

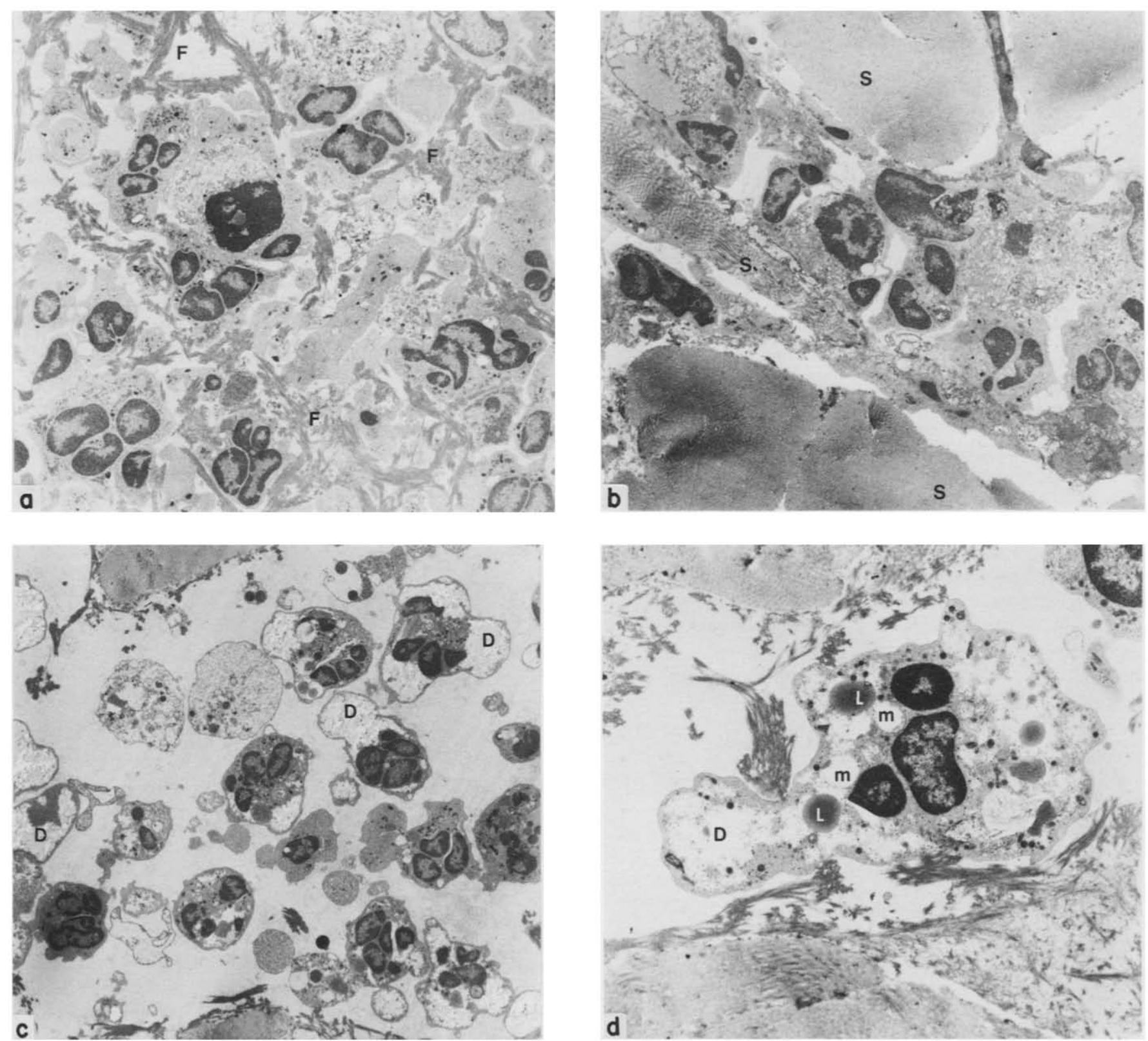

Figure 2 Invading neutrophils entrapped within a fibrin (F) network (d) or between HDSC bundles (S) (b). Imp/antation interval: 2 d (original magnification $\times 4685$ ). (c and d) Deviant morphologv of neutrophils with disintegration (D) of the g/ycogen in the cytoplasm, swollen mitochondria ( $M$ ) and lipid formations ( $L$ ) in HDSC which had been implanted for $5 d(c)$ or $10 d(d)$ loriginal magnification (c) $\times 3226$ and (d) $\times 15360$ ).

Within the implanted HDSC disc, first formation of a fibrin network and cell infiltration occurred (Figures $2 a$ and b). Primarily neutrophils, some macrophages and occasionally a lymphocyte were observed. The neutrophils had an activated morphology, indicated by pseudopod formation and by concentrations of glycogen. These cells were found degenerating in two ways: (1) in a normal pattern as part of a programmed cell death (or apoptosis), characterized by the condensation of the nucleus and degeneration of organelles, or, (2) locally in a deviant pattern, with a still intact nucleus, whilst the glycogen and organelles in the cytoplasm disintegrated and fatty accumulations developed (Figures $2 c$ and $d$ ). These phenomena were observed 1 or $2 \mathrm{~d}$ after implantation in both neutrophils and macrophages in the surrounding connective tissue, but they were most pronounced in the neutrophils within the implant. After $10 \mathrm{~d}$ of implantation deviant neutrophil morphology could still be found, but appeared less intense.

After 2 and $3 d$. HDSC discs became encapsulated as shown by an increase in the number of young fibroblasts and formation of new collagen in the surrounding connective tissue. Fibroblasts were identified by their open face-type nucleus and by an abundance of rough endoplasmic reticulum (RER). Macrophages and also many blasts containing basophil-like granules, further referred to as basophil-like cells, were present. Mitotic figures, signs of cell fusion (Figures $3 a$ and $b$ ) and extensive intra- and extracellular fatty accumulation were observed.

After $5 \mathrm{~d}$, the first signs of ingrowing young fibroblasts and infiltrating basophil-like cells and macrophages were found at the edge of HDSC. Surrounding and internalization of HDSC bundles by macrophages was observed. Cells often contained swollen mitochondria. Furthermore, foreign body multinucleate giant (FBM-G) cells had developed. FBM-G cells showed characteristics of different types of precursor cells, which will be described in detail for the $10 \mathrm{~d}$ implant.

From day 5 to day 10 , infiltration, ingrowth and formation of the different types of FBM-G cells continued. 

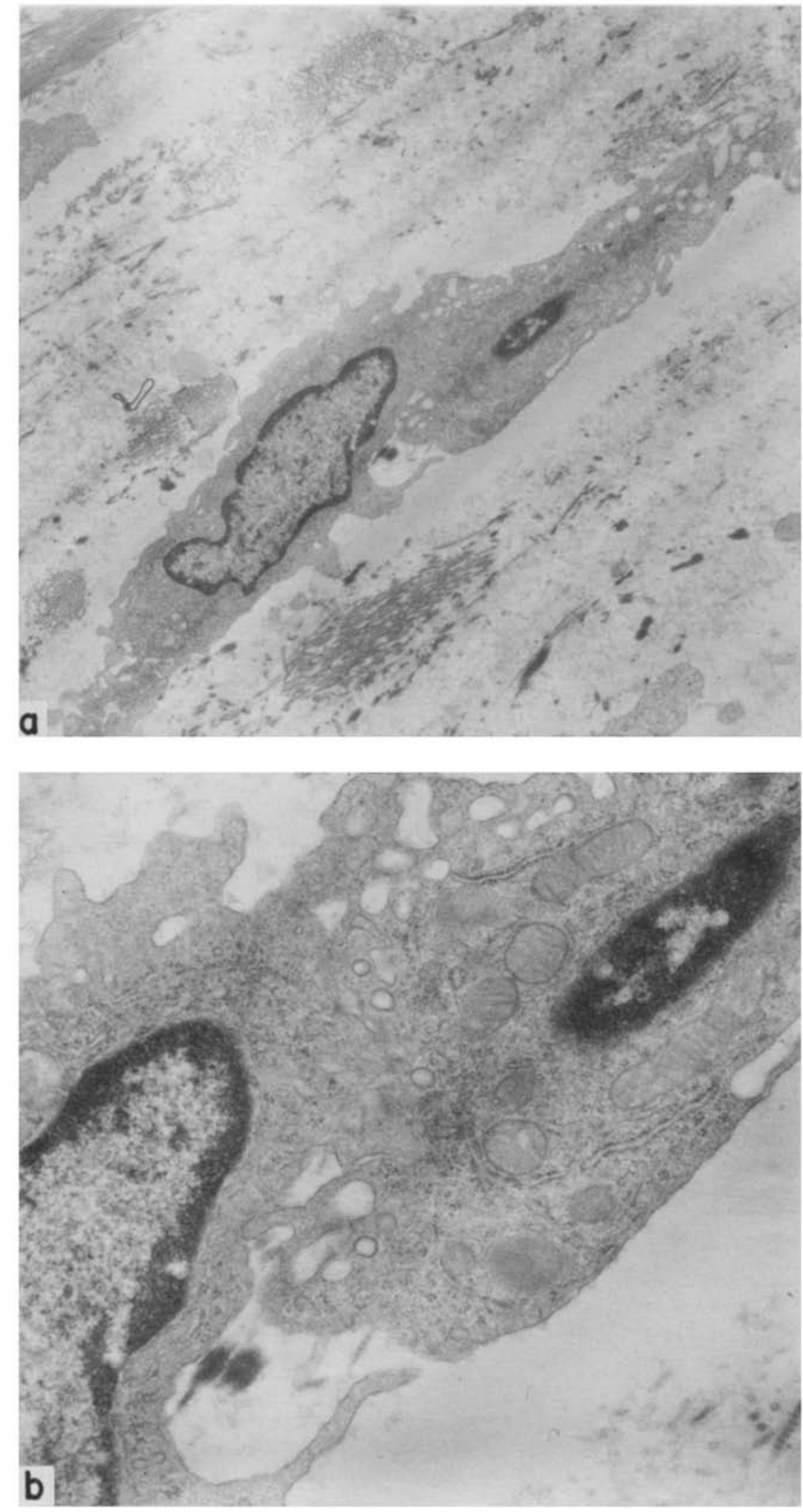

Figure 3 Cell fusion in the connective tissue surrounding the HDSC implant after $3 d$ of implantation (a) and detail shown (b) loriginal magnification (a) $\times 5185$ and (b) $\times 23290)$.

By day 10 , the great variety in cellular interactions compared with other implantation periods was remarkable: the inner interface showed complete ingrowth; the empty central part had a fibrin network, few neutrophils and locally extensive crystalline deposits in HDSC bundles, whereas at the outer interface high numbers of infiltrated neutrophils. sometimes locally showing deviant morphology as described previously, were present.

The inner interface with complete ingrowth contained different cell types, small bundles of newly formed rat collagen constructed of small calibre fibres and blood vessels (Figures $4 a$ and $b$ ). At this interface, ingrowing macrophages, fibroblasts, basophil-like cells and a few capillary buds were present. Amongst the different cell types many FBM-G cells were found especially in the proximity of the fibrous capsule. These FBM-G cells had characteristics of either macrophages, fibroblasts or basophils.

FBM-G cells surrounding and internalizing small parts of sometimes gelatinous HDSC bundles were always either
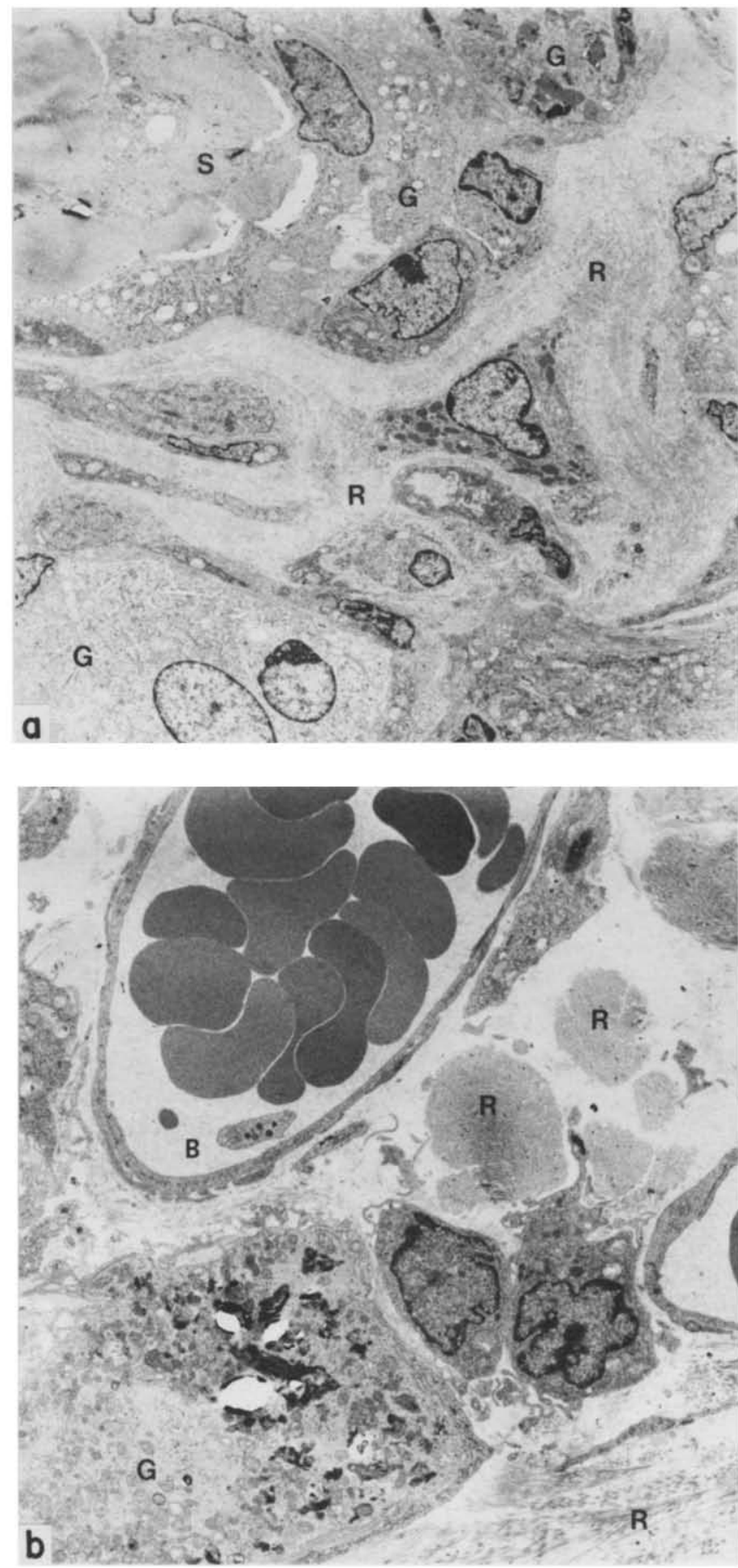

Figure 4 (a and b) Different cell types, e.g. FBM-G cells (G), new/y formed rat collagen $(R)$ and blood vessels $(B)$ in the HDSC (S) implant after 100 (original magnification (a) $\times 3226$ and (b) $\times 4685$ ).

macrophage-like (Figure $5 a$ ) or fibroblast-like (Figure $5 b$ ) FBM-G cells. The macrophage-like FBM-G cells had azurophilic granules and usually many swollen mitochondria and myelin bodies. The fibroblast-like FBM-G cells were characterized by their abundance of RER and the absence of azurophilic granules.

Basophil-like FBM-G cells contained round or semiround granules and/or large multiglobular granules (Figure $6 a)^{11-13}$. Within the round or semiround granules, sometimes membranous structures or whorls, or inclusions of glycogen, or densely packed particles (Figures $6 b$ and $c$ ) were present. The large multiglobular granules sometimes contained fine parallel membranous (Figures $6 d$ and $e$ ) or scroll-like structures (Figure 6f). Accumulations of $\mathrm{Al} / \mathrm{Si}$ crystals and 

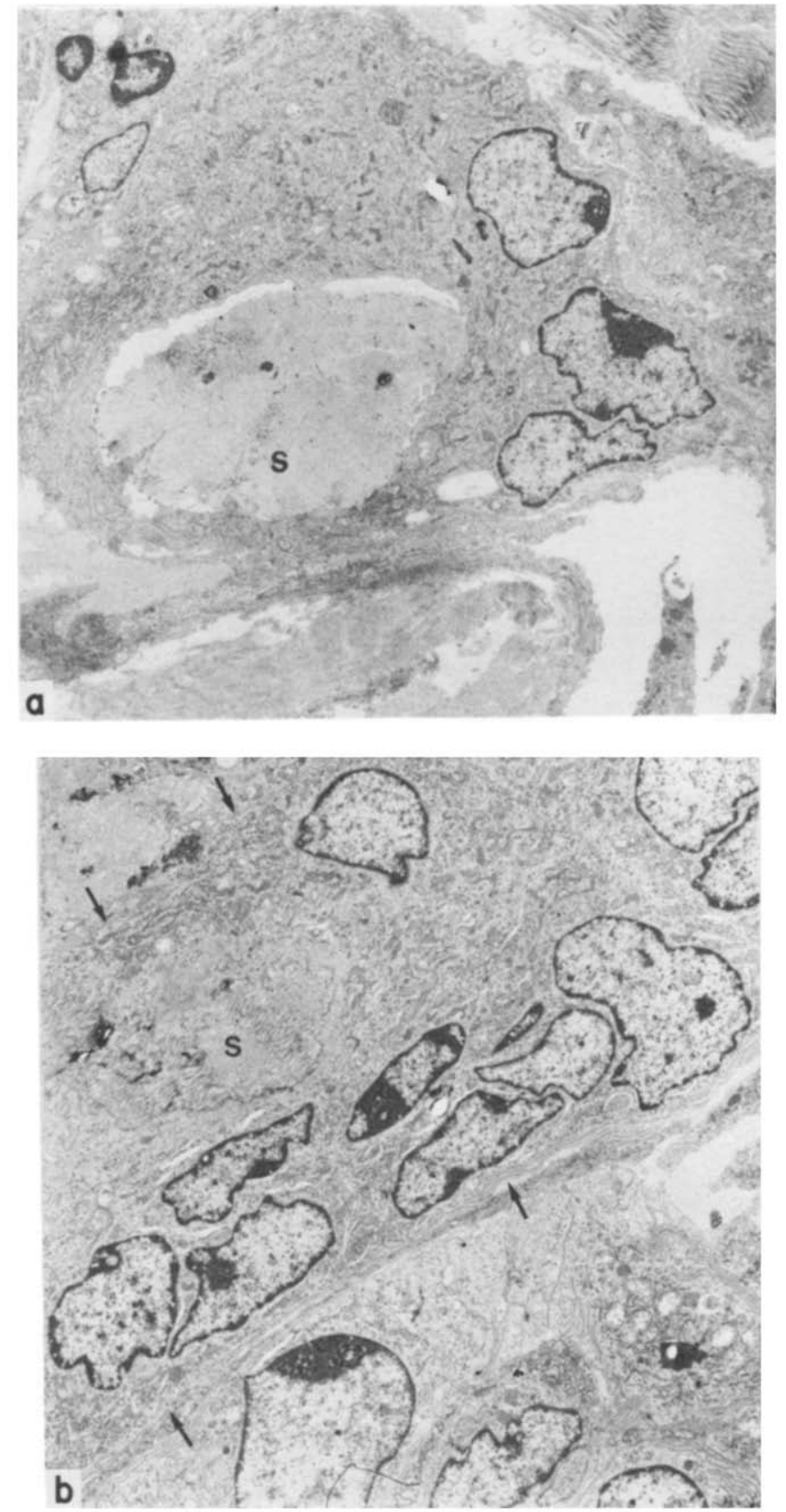

Figure 5 Implantation interval: 10d. (a) Macrophage-like FBM-G cell surrounding HDSC (S) loriginal magnification $\times 4685$ ). (b) Fibroblast-like FBM-G cell internalizing HDSC. The fibroblast-like FBM-G cell contains an abundance of RER (arrows: plasma membrane) foriginal magnification $\times 21043 \%$.

elastin-like substances were particularly present in the granules of basophil-like FBM-G cells (Figure $6 g$ ).

The empty central part of the $10 \mathrm{~d}$ implant contained scattered, sometimes rather extensive, deposits of electrondense needle-like crystals. These crystals were also observed in the 2, 3 and $4 \mathrm{wk}$ implants. Both large bundles of uninternalized HDSC (Figures $7 a$ and $b$ ) and small internalized parts of HDSC showed these crystals, in sharp contrast to newly formed rat collagen. $X$-ray microanalysis showed the presence of calcium $(\mathrm{Ca})$ and phosphorous $(\mathrm{P})$ in these crystals (Figure 8 ). The ratio between the $\mathrm{Ca}$ and $\mathrm{P}$ peaks in these deposits was $1.63+0.09$. indicating the presence of hydroxyapatite. In the 3 and $4 \mathrm{wk}$ implants, some of these deposits showed a clear central part containing only contours of fibrils but no trace elements (Figure 9a). From $10 \mathrm{~d}$ up to $6 \mathrm{wk}$, small deposits of needle-like crystals were occasionally observed free in the cytoplasm (Figure 9b) or within mitochondria of different types of cells. During these time intervals, detachment of fibrils was observed at the interface of both surrounded and internalized parts of HDSC. The presence of gelatinous substances in HDSC did not increase with time.

From about 6 wk HDSC was replaced by rat tissue consisting of newly formed smaller and larger collagen bundles, a well-developed vasculature. FBM-G cells (which were sometimes degenerating), and some fibroblasts, eosinophils and lymphocytes. Newly formed rat collagen contained, especially in the larger bundles, membranous structures (remnants of degenerated cells) entrapped among the fibres (Figure 10). Such membranous structures were not present amongst collagen bundles of the surrounding connective tissue. Both de novo formation and degradation of rat collagen were observed. Degradation occurred by detachment of single fibres, followed by phagocytosis, as well as by obtaining gelatinous appearances. Extracellular $\mathrm{Ca} / \mathrm{P}$ deposits were not found anymore. Blood vessels within the implant contained numerous pinocytotic vesicles in the endothelium and sometimes membranous structures in the lumen. With time, bundles of rat collagen with entrapped membranous structures appeared looser, interspersed with now somewhat smaller, mainly basophil-like, FBM-G cells (Figure 11).

After about $10 \mathrm{wk}$, most basophil-like cells had almost normal sizes. Furthermore, locally degenerating fibroblasts and blood vessels next to fibroblasts and blood vessels with normal morphology were observed.

After $15 \mathrm{wk}$, tissue with difficulty identified during explanation contained few rat collagen bundles not yet similar to collagen bundles in loose connective tissue, interspersed with mainly basophil-like FBM-G cells containing $\mathrm{Al} / \mathrm{Si}$-crystalline accumulations in the granules.

\section{DISCUSSION}

The in vivo degradation of HDSC was studied. HDSC was degraded by both an intra- and an extracellular route and gradually replaced by rat tissue, which was thereafter also degraded. In addition to normal components of a typical foreign body reaction, remarkable phenomena, such as infiltrating neutrophils locally showing deviant morphologies, indications of FBM-G cells derived from different cell types, accumulations of $\mathrm{Al} / \mathrm{Si}$ crystals and depositions of $\mathrm{Ca} / \mathrm{P}$ crystals were observed. After $15 \mathrm{wk}$, the presence of FBM-G cells with $\mathrm{Al} / \mathrm{Si}$ crystals persisted.

HDSC was degraded intracellularly after internalization of small parts by macrophage- and fibroblast-like FBM-G cells. One route of extracellular degradation occurred at the interface of HDSC and the surrounding cells. After some time, both internalized and surrounded HDSC degraded by detachment of fibrils, followed by phagocytosis, but not by obtaining gelatinous appearances. Tanning of HDSC may be a reason for detachment of fibrils taking some time and for not showing gelatin formation. Detachment of fibrils and phagocytosis have been reported before ${ }^{14.15}$. Rat connective tissue replacing HDSC also degraded, possibly as part of a normal tissue-remodelling process. Detachment of fibrils from this tissue had already occurred, whilst at other sites collagen was still being formed de novo. Moreover, rat connective tissue obtained gelatinous morphologies during degradation.

However, $\mathrm{Ca} / \mathrm{P}$-crystalline depositions were not ob- 


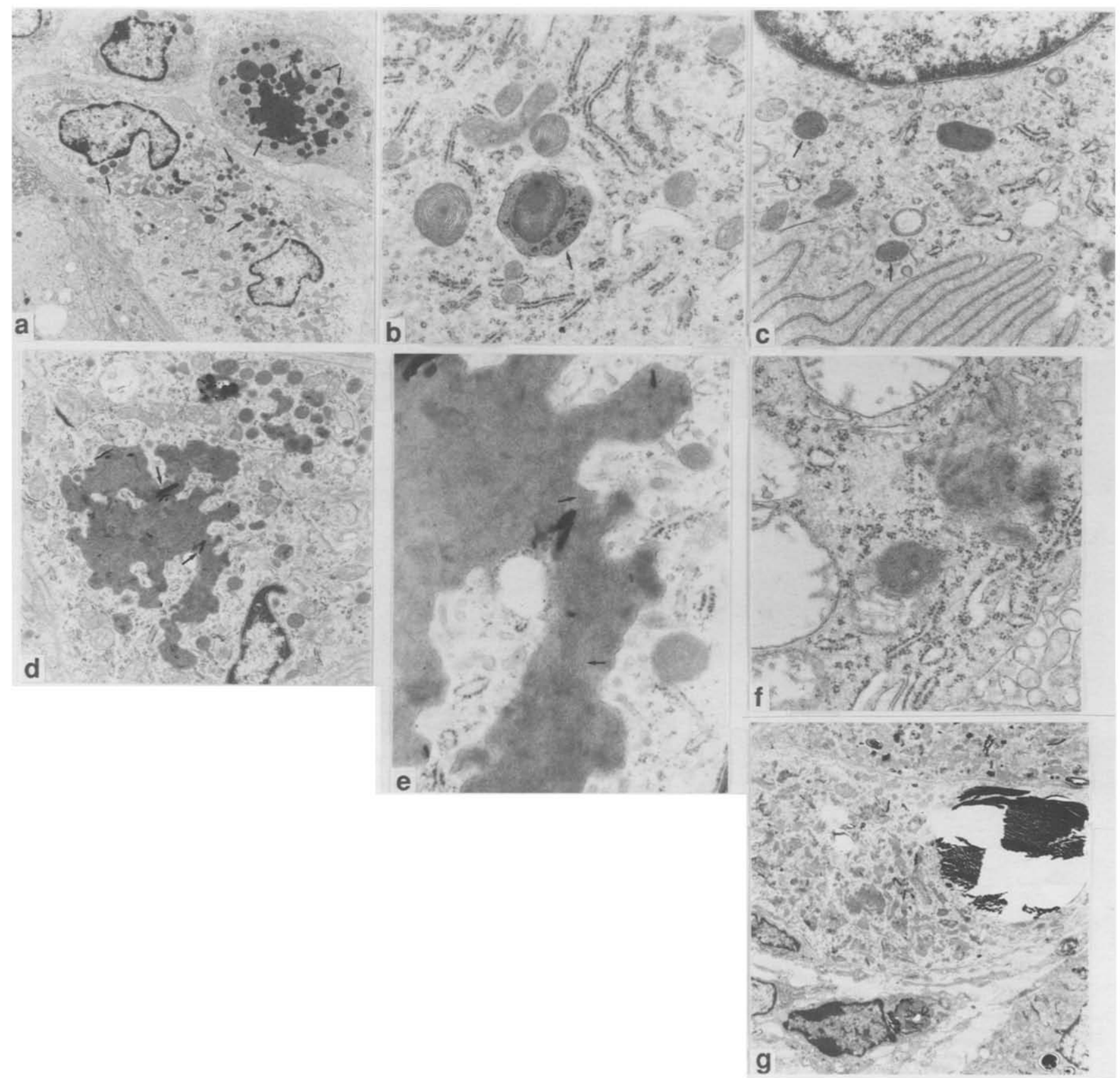

Figure 6 Implantation interval: 10 d. (a) Basophil-like FBM-G cells containing round or semiround granules and/or large multiglobular granules (arrows) (original magnification $\times 7142$ ). (b) Granu/e with included g/ycogen (arrows) loriginal magnification $\times 29184$. (c) Granules with densely-packed particles (arrows) (original magnification $\times 15360$ ). (e) Detail of multiglobular granule (d) with fine parallel membranous structures (arrows) (original magnification $\times 48450$ ). (f) Granule with scroll-like structures (original magnification $\times 48450)$. (g) Accumulation of Al/ Si crystals, which has partiy disappeared due to the preparative procedure (original magnification $\times 7142$ ).

served within this tissue, but only in HDSC; this process in the case of deposition in large HDSC bundles, reflects another route of extracellular degradation. The peak ratio of 1.63 indicates that the deposits consist of hydroxyapatite ${ }^{18.19}$ $\left(\mathrm{Ca}_{10}\left(\mathrm{PO}_{4}\right)_{6}(\mathrm{OH})_{2}\right)$. The deposits and those in internalized HDSC changed their morphology from completely electrondense to partially electron-dense. Since at best only the contours of the original fibrils were present, deposited $\mathrm{Ca} / \mathrm{P}$ crystals were possibly solubilized or phagocytosed and the collagen was replaced by a substance of unknown composition. Calcification of collagen-based bioprostheses has been reported ${ }^{16-18}$. In general, the process of calcification is associated with well-cross-linked collagen fibres, the cross-linker being glutaraldehyde or formaldehyde ${ }^{18}$, and is (e.g. for implanted fixed heart valves) the major cause of failure. This study shows that HMDIC tanning may also result in calcification. The observed sequence of morphologies, i.e. the change from completely electron-dense to cleared central parts and its proposed explanation form a new concept ${ }^{18,19}$. In contrast to HDSC and rat connective tissue which had replaced it, collagen of the surrounding connective tissue did not show evidence of intra- or extracellular degradation. Enzymes may finally play an essential role in degradation of all types of collagen ${ }^{20-21}$.

HDSC was tanned with HMDIC. Only one other group of investigators reported on the use of collagen tanned with $\mathrm{HMDIC}^{4,22}$. These researchers did not light microscopically observe any morphological deviations using HMDIC-tanned burn dressings and collagen sponges, from which they concluded that toxicologically MDIC is a quite acceptable 

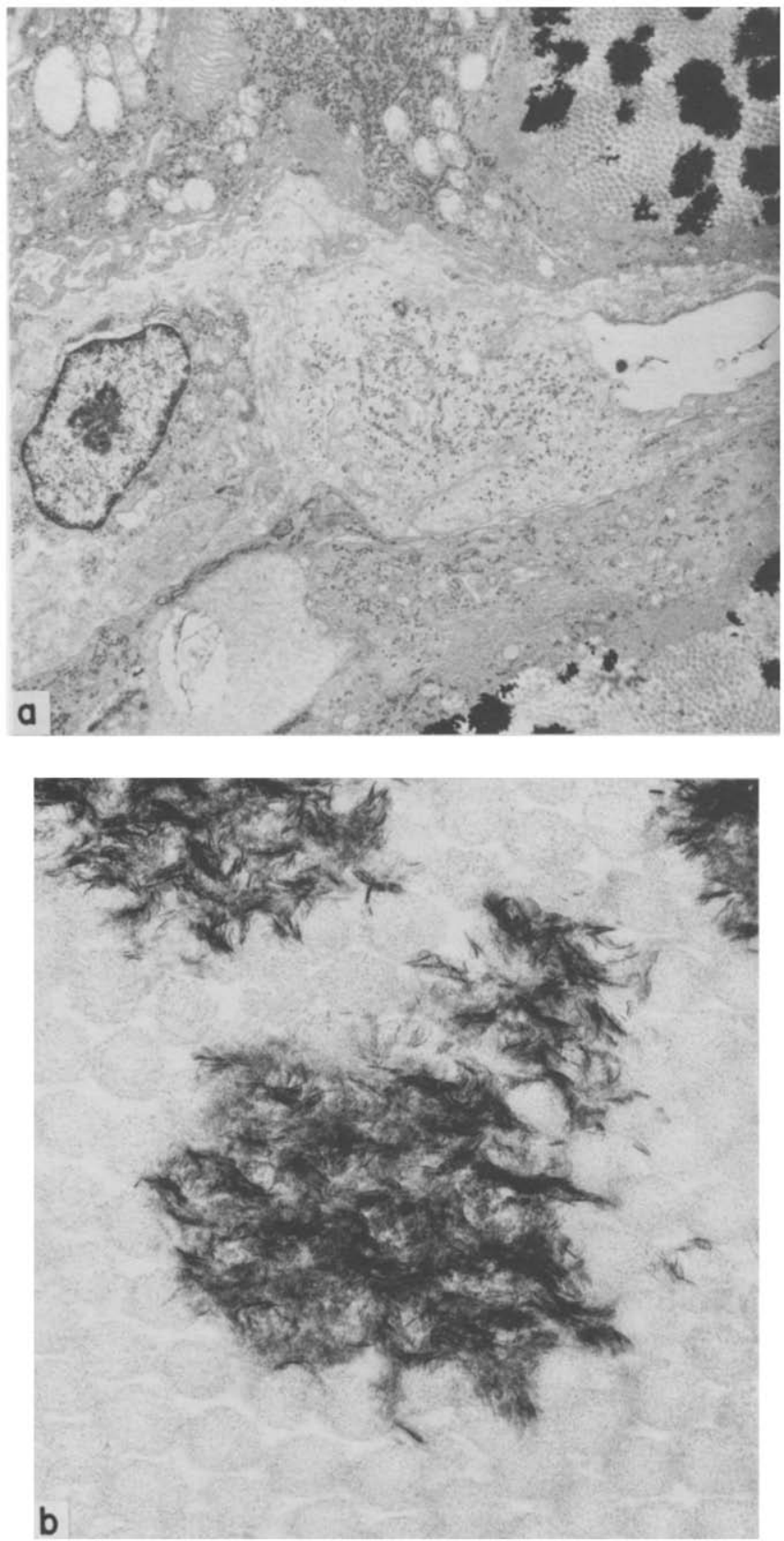

Figure 7 Electron-dense deposits of needle-fike crystals present in HDSC bundles after 2 wk of implantation (original magnification (a) $\times 7142$ and (b) $\times 15360$ ).

tanning agent. In contrast, we made observations that suggest cytotoxicity. Cytotoxic effects of diisocyanates have been reported ${ }^{23-26}$ and the hydrolysis product of HMDIC, diaminohexane (DAH). which may leak from HDSC was also shown to have cytotoxic effects ${ }^{27-29}$.

One of the indications for cytotoxicity is the deviant morphology of neutrophils, which is not described in normal wound healing ${ }^{30}$, cell-biomaterial interactions in general ${ }^{31-33}$ or more specific cell-collagen interactions ${ }^{1-6}$. This deviant morphology of neutrophils was observed soon after implantation in both the surrounding connective tissue and within the implant, and by day 10 was still observed within the implant. This clearly indicates primary cytotoxic effects of HDSC. We define primary cytotoxic effects as effects resulting from direct release of cytotoxic substances (possibly DAH) in contrast to secondary cytotoxic effects with release of cytotoxic substances as a consequence of HDSC degradation

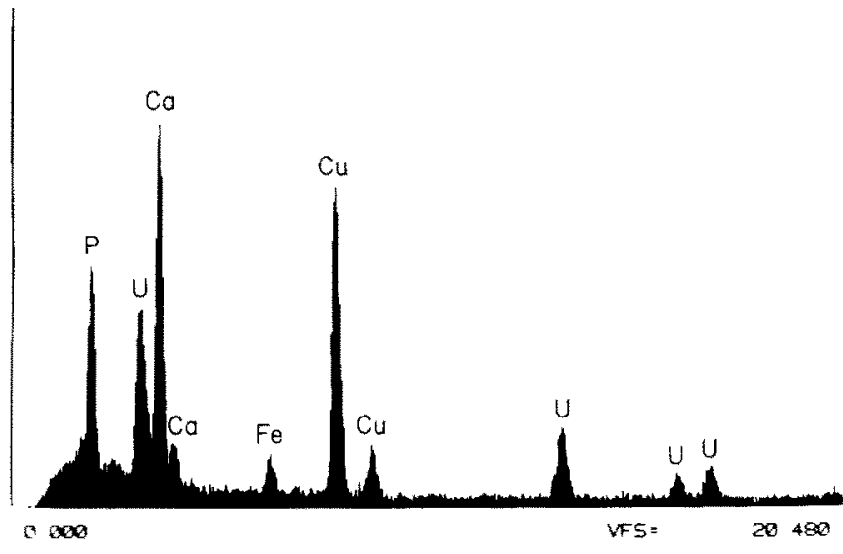

Figure 8 Spectrogram of needle-like crystal on HDSC bundle showing phosphorus $(P)$ and calcium ( $C$ a). The elements $U$ and $C u$ were derived from the preparative procedure. The element Fe was present in the specimen nearby the crystalline deposit.
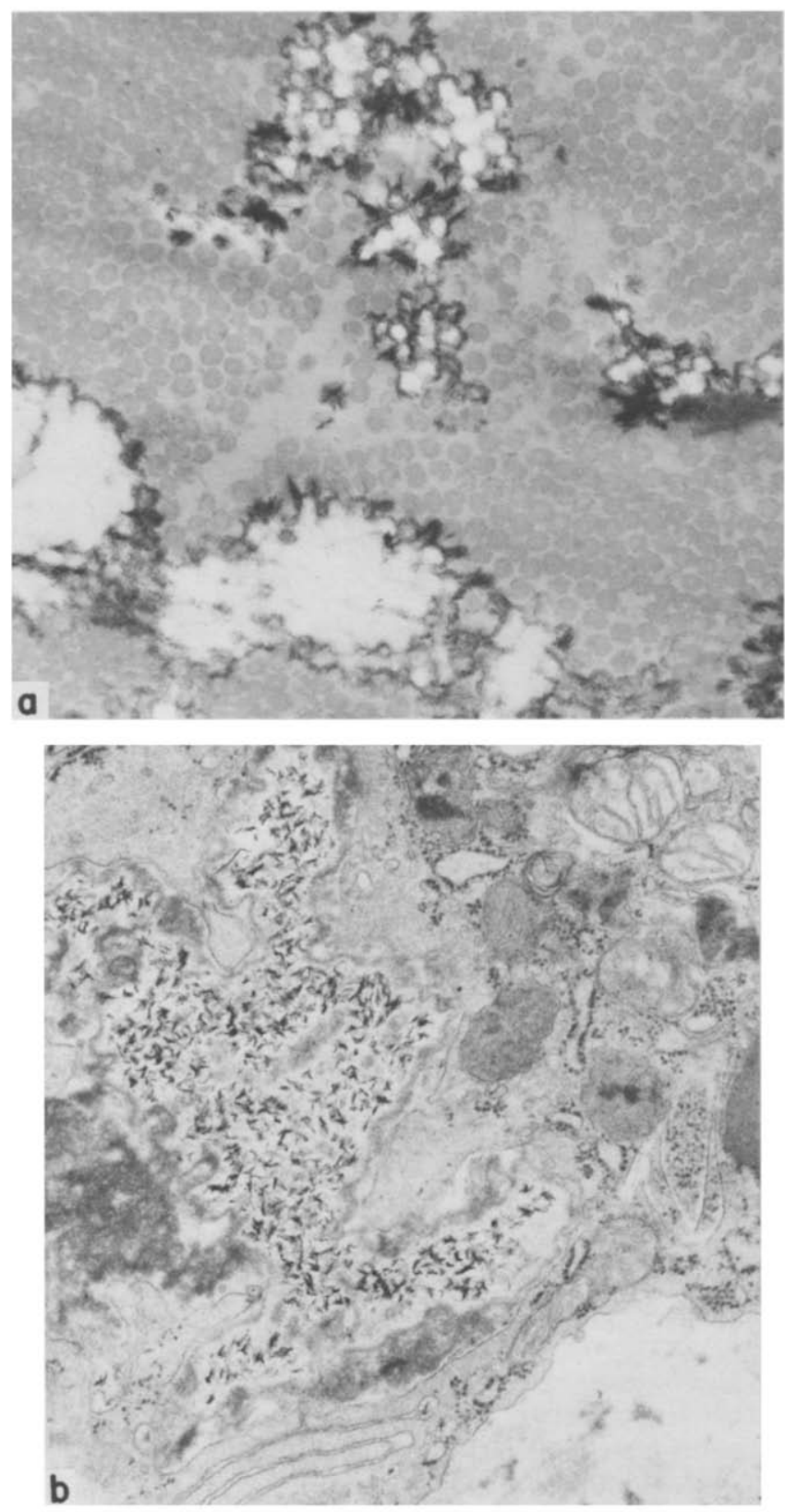

Figure 9 (a) Deposits of Ca/P crystals with cleared central parts containing the contours of fibrils but no trace elements 4 wik after implantation loriginal magnification $\times 133601 .(b) \mathrm{Ca} / \mathrm{P}$ crystals are present in the cytoplasm of a $F B M-G$ cell 5 wk after implantation (original magnification $\times 29184$ ) 


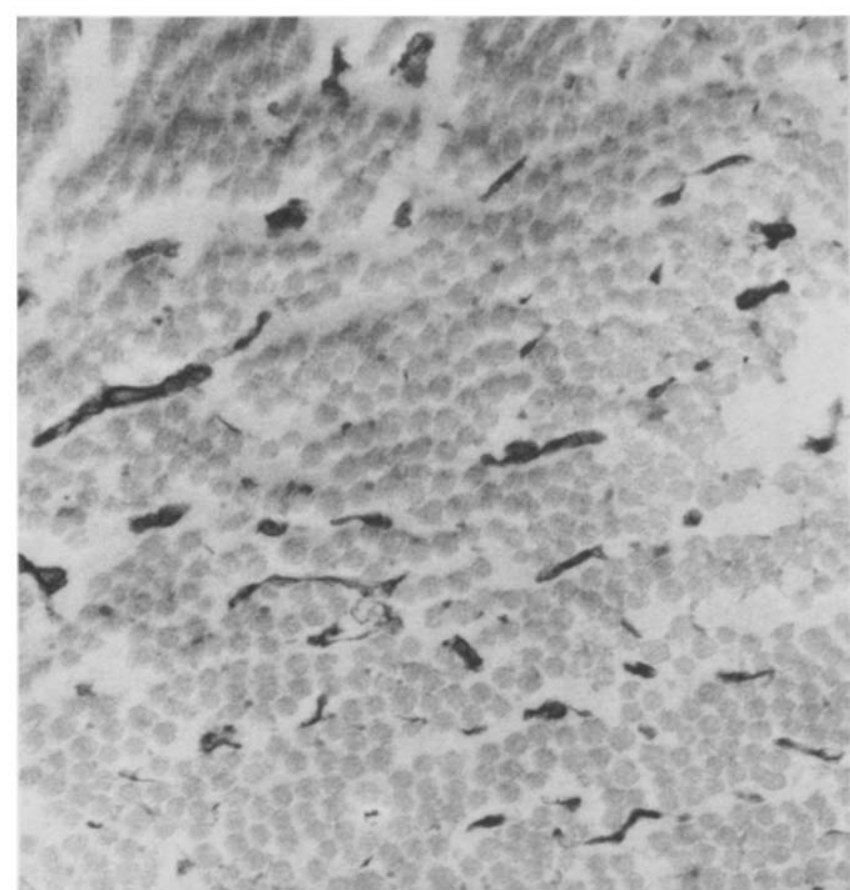

Figure 10 Membranous structures, probably from degenerated cells, entrapped within a bundle of newly formed rat collagen (original magnification $\times 29$ 184).

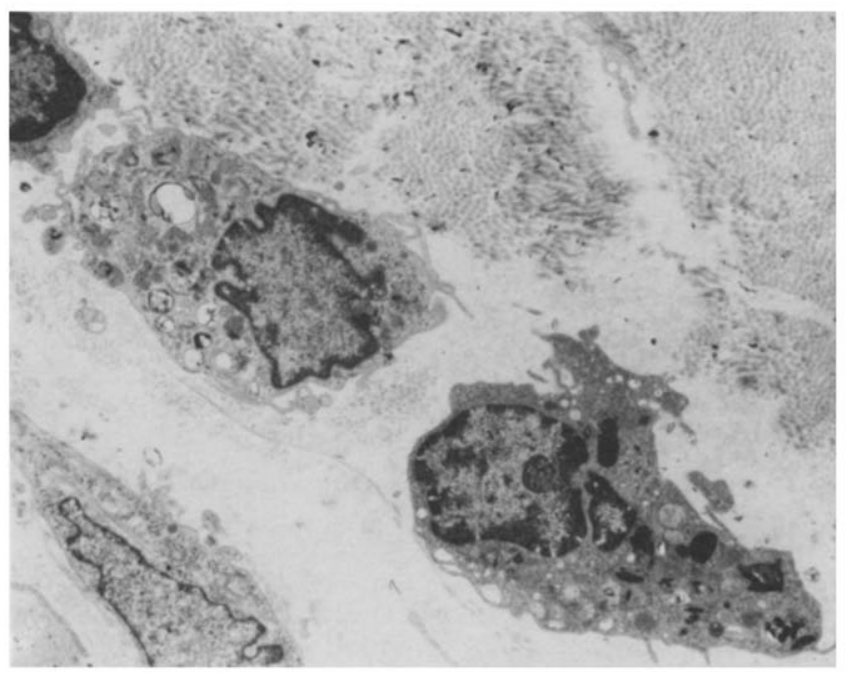

Figure 11 Rather loose rat collagen interspersed with smaller basophilike FBM-G cells, containing Al/Si-crystalline accumulations foriginal magnification $\times 7905$ )

by cells. Primary cytotoxicity can be removed by extensive washing of HDSC, preliminary results indicated that a washed HDSC implant did not show deviant morphology of neutrophils shortly after implantation. In contrast, secondary cytotoxic effects cannot be prevented by washing, as detected by us in an in vitro biocompatibility test ${ }^{34}$. In our study it is difficult to discriminate between primary and secondary cytotoxicity, with one changing gradually into the other.

Apart from deviant neutrophil morphology, cytotoxicity may also be reflected by the extensive presence of both intraand extracellular lipid ${ }^{35}$, of cells with swollen mitochondria and of the high number of infiltrating basophil-like cells and basophil-like FBM-G cells.

We characterized basophil-like cells by the morphology of the granules, which are typical for basophils, or cells of basophil origin, but not for macrophages ${ }^{11,12}$. Basophiloriginating cells are normally involved in inflammatory responses related with infections and allergies; they have phagocytic capacity and can pinocytose ${ }^{11-13}$. The chemoattractant responsible for enhanced presence of basophillike cells is as yet unknown, although $\mathrm{Al} / \mathrm{Si}$ crystals may be candidates, since the FBM-G cells formed from basophil-like cells accumulated them.

Formation of FBM-G cells from basophil-like cells has not been described before ${ }^{36-40}$. Basophil-like FBM-G cells sometimes contained both rather active and inactive nuclei which validates the hypothesis of formation by fusion. We cannot exclude the possibility of the multiglobular granules in basophil-like FBM-G cells consisting only of phagocytosed degenerated material, although this is unlikely since parallel membranous or scroll-like structures are not expected within the granule. Therefore, apart from granule morphology. other techniques have to provide further proof of the origin of basophil-like (FBM-G) cells and the possibility of extension of the current theory on FBM-G cells ${ }^{36-40}$.

The formation of FBM-G cells from macrophages has often been reported in cell-biomaterial interactions. Current theory on FBM-G cells says that they are formed from macrophages by fusion ${ }^{36-40}$, although formation by nuclear division is not excluded. Also in this study, macrophages and macrophage-like FBM-G cells were observed. The attracting signal for macrophages and macrophage-like FBM-G cells may be the HDSC collagen itself. The development of fibroblast-like FBM-G cells, which we discriminated from the macrophage-like FBM-G cells by their abundance of RER and the absence of small azurophilic granules, has been suggested previously ${ }^{37}$. Both macrophage-and fibroblast-like FBM-G cells were possibly formed by fusion of cells, since, in some cases, cells simultaneously containing both rather active and inactive nuclei were observed.

The presence of $\mathrm{Al} / \mathrm{Si}$ crystals is difficult to explain. Part of these structures was already present in HDSC before implantation and may have been introduced during some step in the fabrication procedure. But this cannot explain the extent of $\mathrm{Al} / \mathrm{Si}$ crystals observed. So we believe that they were in part newly formed and further accumulated during degradation ${ }^{41}$. Crystallization may occur since both silicon and aluminium are at hand. Si is an essential trace element present in all kinds of body fluids and connective tissues and is required for collagen biosynthesis ${ }^{42-45}$. Therefore, HDSC may function as a possible source of $\mathrm{Si}$. Blood is the possible source of $\left.A\right|^{46,47}$. Si and $A l$ are known to readily combine and the formation of aluminium silicates at physiological $\mathrm{pH}$ has been described ${ }^{46}$. The presence of aluminium silicates has been reported for brain tissue and related with Alzheimer's disease 45-47 $^{\text {. }}$

Detailed knowledge on collagen degradation was obtained from this study, which may in general be of use for a better understanding and further improvement of collagenbased biomaterials. Degradation of HDSC was compared with degradation of rat collagen from the replaced HDSC and with collagen of the fibrous capsule. Remarkable phenomena observed during HDSC degradation are related to this specific material and suggest cytotoxicity. Cytotoxicity may occur as a result of tanning. Tanning agents will always be released in some way, which remains a point of concern. Primary cytotoxic substances of HDSC may be removed by extensive washing, but secondary cytotoxic substances not. However, cytotoxic effects have also been reported for certain clinically applied collagen-based bioprostheses. For example, porcine heart valves leak toxic substances (GA), but it is claimed that this improves their function by prevention of cell ingrowth and therefore degradation ${ }^{48}$. 
It is concluded that this study emphasizes the need for detailed evaluation at the ultrastructural level of newly developed biomaterials as signs of cytotoxicity can be detected to advantage using this observation method.

\section{REFERENCES}

1 Chvapil, M., Kronenthal, R.L. and Van Winkle, W., Medical and surgical applications of collagen, in Int. Rev. Conn. Tissue Res. Vol. 6. (Eds D.A. Hall and D.S. Jackson). Academic Press, London, UK, 1973. pp. 1-61

2 Pharriss, B.B., Collagen as a biomaterial, J. Am. Leather Chem. Assoc. $1980,75,474-485$

3 Huc, A., Collagen biomaterials: characteristics and applications, J. Am. Leather Chem. Assoc. 1985, 80, 195-212

4 Chvapil, M., Speer, D., Mora, W. and Eskelson, C., Effect of tanning agent on tissue reaction to tissue implanted collagen sponge. $J$. Surg. Res. 1983, 35, 402-409

5 Gorham, S.D., Hyland, T.P., French, D.A. and Willins, M.J., Cellular invasion and breakdown of three different collagen films in the lumbar muscie of the rat, Biomaterials 1990, 11 113-118

6 Srivastava, S., Gorham, S.D. and Courtney, J.M., In vivo evaluation and comparison of collagen, acetylated collagen and collagen/glycosaminoglycan composite films and sponges as candidate biomaterials, Biomaterials 1990, 11, 155-161

7 Van Gulik, T.M., Christianu, R.A., Broekhuizen, A.H., Raaymakers, E.L.F.B. and Klopper, P.J., A tanned, sheep dermal collagen graft as a dressing for split-skin graft donor sites, Neth. J. Surg. 1989, 41, 65-67

8 Kuper, C.F., Prinsen, M.K. and Roverts, W.G., Intramuscular implantation test in rabbits with lower split sheepskin (LS-HMDIC-130), TNO Report No. V87. 068/260654 Netherlands Organization for Applied Scientific Research, Zeist, The Netherlands, February, 1987

9 Roverts, W.G. and Kuper, C.F., Intracutaneous test with extracts from lower-split sheepskin (LS-HMDIC-130) in albino rabbits, TNO Report No. V86.513/260656 Netherlands Organization for Applied Scientific Research, Zeist, The Netherlands, November, 1986

10 De Bruyn, W.C., Koerten, H.K., Cleton-Zoeteman, M.I. and Blok van Hoek, C.J.G., Image analysis and X-ray microanalysis in cytochemistry, Scanning Microsc. 1987, 1(4) 1651

11 Zucker-Franklin, D., Greaves, M.F., Grossi, C.E. and Marmont, A.M., Atlas of Blood Cells, Function and Pathologv Edizone Ermes, Milano, Italy, 1981

12 Bessis, M. and Weed, R.I., Living Blood Cells and Their U/trastructure Springer-Verlag, New York, USA, 1973

13 Galli, S.J., Biolugy of disease: New insights into 'The riddle of mast cells': Microenvironmental regulation of mast cell development and phenotypic heterogeneity, Lab. Invest. 1990, 62, 5-33

14 Everts, V., Phagocytosis and intracellular digestion of collagen fibrils, PhD Thesis, University of Amsterdam, The Netherlands, 1987

15 Yajima, T., Acid phosphatase activity and intraceltular collagen degradation by fibroblasts in vitro, Cell Tissue Res. 1986, 245. 253-260

16 Strates, B., Lian, J. and Nimni, M.E., Calcification in cardiovascular tissues and bioprostheses, in Collagen Vol. III, Biotechnology, (Ed. M.E. Nimni), CRC Press, Boca Raton, Florida, USA, 1988. pp. 273-292

17 Ferrans, V.J., Hilbert, S.L., Tomita, Y., Jones, M. and Roberts, W.C., Morphology of collagen in bioprosthetic heart valves, in Collagen Vol. III, Biotechnology, (Ed. M.E. Nimni), CRC Press, Boca Raton, Florida, USA, 1988, pp. 145-189

18 Levy, R.I., Schoen, F.J., Sherman, R.S., Nichols, J.. Hawley, M. A and Lund, S.A., Calcification of subcutaneously implanted type I collagen sponges: effects of formaldehyde and glutaraldehyde pretreatments. Am. J. Pathol, 1986, 122, 71

19 Schoen, F.J., Harasaki, H., Kim, K.M., Anderson, H.C. and Levy, R.J., Biomaterial-associated calcification: Pathology, mechanisms, and strategies for prevention, J. Biomed. Mater. Res.: Appl. Biomaterials 1988, 22 (A1), 11-36

20 Murphy, G. and Reynolds, J.J., Current views of collagen degradation. Progress towards understanding the resorption of connective tissues, BioEssays $1985,2,55-60$

21 Laurent, G.J., Dynamic state of collagen: pathways of collagen degradation in vivo and their possible role in regulation of collagen mass, Am. J. Physiol. 1987, 252, Cl-C9
Chvapil, M., Considerations on manufacturing principles of a synthetic burn dressing: a review, J. Biomed. Mater. Res. 1982, 16, 245-263

23 Kennedy, G.L., Rayanne, L., Ferenz, L. and Burgess, A., Estimation of acute oral toxicity in rats by determination of the approximate lethal dose rather than the LD50, J. Appl. Toxicol. 1986, 6 (3), 145-148

24 Brown, W.E., Green, A.H., Karol, M.H. and Alarie, Y.C.E., Inhibition of cholinesterase activity by isocyanates, Toxicol. Appl. Pharmacol. 1982, 63, 45-5?

25 Chang, K.C. and Karol, M.H., Diphenylmethane disocyanate (MDI)induced asthma: evaluation of the immunologic responses and application of an animal model of isocyanate sensitivity, C/in. A//ergy 1984,14 (4), 329-339

26 Träubel, H., Gerbungen mit Isocyanatderivaten, Das Leder 1977, 2 (11), 181-185

27 Berode, M., Leuenberger, Ph. and Savolainen, H., Phenotype-hexanediamine in vitro, Biochem. Int. 1988, 17, 1

28 Yanc, E. Yoshioka, M. and Koizumi, A. Relationship between chemical structure and cytotoxicity of aliphatic amines examined by a microtiter systcm with cultured fibroblasts, Jap. J. Ind. Health 1981, 23 , 537-543

29 Johannsen, F.R. and Levinskas, G.J., Toxicological profile of orally administered 1,6-hexane diamine in the rat. J. Appl. Toxicol. 1987,7 (4). 259

30 Robbins, S.L., Pathologic basis of disease, 4th Ed., W.B. Saunders Co., Philadelphia. Pennsylvania, USA, 1989, pp. 1-86

31 Williams, D.F. Tissue-biomaterial interactions, review, J. Mater. Sci. $1987,22,3421-3445$

32 Ziats, N.P., Miller, K.M. and Anderson, J.M., In vitro and in vivo interactions of cells with biomaterials, Biomaterials $1988,9,5-13$

33 Woodward, S.C. and Salthouse, T.N., The tissue response to implants and its evaluation by light microscopy, in Handbook of Biomaterials Evaluation: Scientific, Technical and Clinical Testing of Implant Materials (Ed. A.F. von Recum), Macmillan Publishing Co.. New York, USA, 1986, pp. 367-378

34 Luyn, van, M.J.A., Wachem, van, P.B., Olde Damink, L., Ten Hoopen, H. Feijen, J. and Nieuwenhuis, P., Methylcellulose culture as a new and sensitive in vitro biocompatibility test system Materials in Medicine (in press)

35 Weiss, L., Cell and Tissue Biology Textbook of Histology, Sixth Edn. Urbun and Schwarzenberg, Baltimore, USA, 1988, pp. 157-209

36 Mariano, M. and Spector, W.G., The formation and properties of macrophage polykaryons (inflammatory giant cells), J. Pathol. 1974, $113(1), 1-19$

37 Chambers, T.J., Multinucleate giant cells, J. Pathol. 1978, 126 (3). 125-148

38 Papadimitriou, J.M. and Walters, M.N., Macrophage polykarya, in CRC Clinical Reviews in Toxicology CRC Press Inc., Boca Raton. Florida, USA, 1979, Vol. 6, pp. 211-255

39 Murch, A.R., Grounds, M.D., Marshall, C.A. and Papadimitriou, J.M. Direct evidence that inflammatory multinucleate giant cells form by fusion, J. Pathol. 1982, 137, 177-180

40 Schlesinger, L.. Musson. R.A. and Johnston, R.B., Functional and biochemical studies of multinucleated giant cells derived from the culture of human monocytes. J. Exp. Med. 1984, 159, 1289-1294

41 Koerten, H.K., Blitterswijk, C.A., van, Grote, J.J. and Daems, W.Th Accumulation of trace elements by macrophages during degradation of biomatcrials, in Implant Materials in Biofunction. Advances in biomaterials, Vol. 8, (Eds C. de Putter, C.L. Lange, K. de Groot and A.J.C. Lee), Elsevier Science Publishers, Amsterdam. The Netherlands pp. $43-48$

42 Carlisle, E.M., Silicon: an essential element for the chick, Science $1972,178,619-62$

43 Schwarz, K. and Milne, D.B., Growth-promoting effects of silicon in rats, Nature 1972, 239, 333-334

44 Nielsen. F.H. Newer trace elements in Trace Elements in Human Health and Disease Vol. II, Essential and toxic elements, (Ed. A.S. Prasad). Academic Press, New York, USA, 1976, pp. 390-399

45 Carlisle, E.M. The nutritional essentiality of silicon, Nutr. Rev. 1982 40 (7), 193-198

46 Birchalt, J.D. and Chappell, J.S., The chemistry of aluminium and silicon in relation to Alzheimer's disease, Clin. Chem. 1988, 34 (2), 265-267

47 Carlisle, E.M. and Curran, M.J., Effect of dietary silicon and aluminum on silicon and aluminum levels in rat brain, Alzheimer Disease and Associated Disorders 1987, 1 (2), 83-89

48 Speer, D.P., Chavpil, M., Eskelson, C.D. and Ulreich, J., Biological effects of residual glutaraldehyde in glutaraldehyde-tanned collagen biomaterials, J. Biomed. Mater. Res. 1980, 14, 753-764 